\title{
Risk of atrial fibrillation among bisphosphonate users: a multicenter, population-based, Italian study
}

\author{
L. Herrera • I. Leal • F. Lapi • M. Schuemie • V. Arcoraci • F. Cipriani • E. Sessa • \\ A. Vaccheri • C. Piccinni • T. Staniscia • A. Vestri • M. Di Bari • G. Corrao • \\ A. Zambon • D. Gregori • F. Carle • M. Sturkenboom • G. Mazzaglia • G. Trifiro
}

Received: 11 February 2014 / Accepted: 23 December 2014 / Published online: 10 March 2015

(C) The Author(s) 2015. This article is published with open access at Springerlink.com

\begin{abstract}
Summary Bisphosphonate treatment is used to prevent bone fractures. A controversial association of bisphosphonate use and risk of atrial fibrillation has been reported. In our study, current alendronate users were associated with a higher risk of atrial fibrillation as compared with those who had stopped bisphosphonate (BP) therapy for more than 1 year.

Introduction Bisphosphonates are widely used to prevent bone fractures. Controversial findings regarding the association between bisphosphonate use and the risk of atrial fibrillation (AF) have been reported. The aim of this study was to evaluate the risk of AF in association with BP exposure.
\end{abstract}

Electronic supplementary material The online version of this article (doi:10.1007/s00198-014-3020-y) contains supplementary material, which is available to authorized users.

\section{Herrera}

Department of Internal Medicine, Erasmus Medical Center

University, Rotterdam, Netherlands

I. Leal $\cdot$ M. Schuemie $\cdot$ M. Sturkenboom $\cdot$ G. Trifiro $(\bowtie)$

Department of Medical Informatics, Erasmus University Medical

Center, Rotterdam, Netherlands

e-mail: trifirog@unime.it

F. Lapi $\cdot$ F. Cipriani $\cdot$ E. Sessa $\cdot$ G. Mazzaglia

Regional Agency for Healthcare Services of Tuscany, Florence, Italy

V. Arcoraci $\cdot$ G. Trifiro

Department of Clinical and Experimental Medicine, University of

Messina, Messina, Italy

A. Vaccheri $\cdot$ C. Piccinni

Department of Medical and Surgical Sciences, University of

Bologna, Bologna, Italy

\section{T. Staniscia}

Department of Medicine and Aging, University "G. d'Annunzio",

Chieti-Pescara, Italy
Methods We performed a nested case-control study using the databases of drug-dispensing and hospital discharge diagnoses from five Italian regions. The data cover a period ranging from July 1, 2003 to December 31, 2006. The study population comprised new users of bisphosphonates aged 55 years and older. Patients were followed from the first BP prescription until an occurrence of an AF diagnosis (index date, i.e., ID), cancer, death, or the end of the study period, whichever came first. For the risk estimation, any AF case was matched by age and sex to up to 10 controls from the same source population. A conditional logistic regression was performed to obtain the odds ratio with $95 \%$ confidence intervals (CI). The BP exposure was classified into current ( $<90$ days prior to ID), recent

\footnotetext{
A. Vestri

Department of Public Health and Infectious Diseases, University

"La Sapienza", Rome, Italy
}

M. Di Bari

Research Unit of the Medicine of Aging, Department of Experimental and Clinical Medicine, University of Florence and Azienda Ospedaliero-Universitaria Careggi, Florence, Italy

G. Corrao $\cdot$ A. Zambon

Department of Statistics and Quantitative Methods, University of Milano-Bicocca, Milan, Italy

D. Gregori

University of Turin, Turin, Italy

F. Carle

The Università Politecnica Delle Marche, Ancona, Italy 
(91-180), past (181-364), and distant past ( $\geq 365)$ use, with the latter category being used as a reference point. A subgroup analysis by individual BP was then carried out.

Results In comparison with distant past users of $\mathrm{BP}$, current users of BP showed an almost twofold increased risk of AF: odds ratio $(\mathrm{OR})=1.78$ and $95 \% \mathrm{CI}=1.46-2.16$. Specifically, alendronate users were mostly associated with $\mathrm{AF}$ as compared with distant past use of BP (OR, 1.97; $95 \%$ CI, 1.59-2.43). Conclusion In our nested case-control study, current users of $\mathrm{BP}$ are associated with a higher risk of atrial fibrillation as compared with those who had stopped BP treatment for more than 1 year.

Keywords Alendronate - Atrial fibrillation . Bisphosphonates $\cdot$ Nested case-control study

\section{Introduction}

Bisphosphonates are the most widely prescribed drugs for the treatment of osteoporosis worldwide [1,2]. These drugs inhibit osteoclastic bone resorption, thus increasing bone density and reducing the risk of fractures [3, 4]. Bisphosphonates available on the market include alendronate, risedronate, etidronate, ibandronate, and the more recently marketed zoledronic acid [5-7]. On the whole, bisphosphonates are safe, although their use is limited by several adverse effects such as gastrointestinal disturbances, musculoskeletal pain, and acute phase reactions. More severe adverse reactions such as osteonecrosis of the jaw (ONJ), hypersensitivity, kidney disorders, and emerging safety signals such as atrial fibrillation (AF) have been rarely observed $[6,8,9]$. In particular, AF has been detected as a potential signal of intravenous zoledronic acid and oral alendronate treatment in postmenopausal women [10-13]. According to Cummings [14], parenteral administration of bisphosphonates may increase the release of inflammatory cytokines which have been associated with AF.

The HORIZON (Health Outcomes and Reduced Incidence with Zoledronic Acid Once Yearly) study showed an increased risk of serious AF in patients receiving a yearly infusion of zoledronic acid when compared with a placebo (50 vs. 20 patients; $p<0.001$ ) $[12,15]$. In the FIT (Fracture Intervention Trial) study, a trend towards an increased risk of AF with the use of alendronate compared to that of a placebo was observed, although this finding did not exhibit the statistical significance (relative risk, 1.14; $95 \%$ confidence intervals (CI), 0.83-1.57) [14, 16]. Furthermore, a few populationbased case-control studies reported controversial results concerning the association between use of alendronic acid and AF risk [11-13, 17-21]. In light of the current scientific evidence, the US Food and Drug Administration (FDA) noted that no firm conclusions could be drawn concerning relationships between AF and bisphosphonate treatment [22].

$\mathrm{AF}$ is considered the most important type of cardiac arrhythmia in the elderly population, and it is a potential trigger for fatal strokes, thromboembolism, and worsening heart failure. The known risk factors of AF are heart failure, diabetes, hypertension, myocardial infarction, and smoking, among others [23-26], and given the frequency and clinical relevance of $\mathrm{AF}$, further studies are urgently needed to verify whether bisphosphonate (BP) use may truly represent a risk factor for AF. No studies of the relationship between BP use and AF onset have been conducted thus far in Italy. Accordingly, the aim of this population-based database study was an assessment of the association of bisphosphonate use with $\mathrm{AF}$ risk in Italian adults aged 55 years or more, by employing a nested case-control study in a cohort of new users of BP.

\section{Methods}

\section{Data sources}

Data for this study were obtained from the Bisphosphonates Efficacy-Safety Trade-off (BEST), a multicenter observational study sponsored by the Italian Pharmaceutical Agency (Agenzia Italiana del Farmaco, AIFA), whose design and primary results have been published previously [27]. The data sources were outpatient drug-dispensing and hospital discharge diagnoses from ten local health authorities (LHAs) in five Italian regions, which covered a population of about 18 million citizens from July 1, 2003 to December 31, 2006. In this database network, drug dispensing is coded according to the Anatomical Therapeutic Chemical (ATC) classification system, while hospital discharge diagnoses are coded using the International Classification Disease 9th version-Clinical Modification (ICD-CM). Fully anonymous patient-level data from participating centers were combined in a unique central data warehouse, and the ethical committee of each participating LHA approved the study.

\section{Cohort selection}

People aged 55 years and over with at least one BP prescription during the study period were recruited, and the date of their first dose was used as their entry into the study. Only new users (with no previous prescription of BP within a 6-month period prior to entry in the study) were included.

Subjects with a history of hospitalization due to malignant neoplasm (ICD-9: 140 to 208) or atrial fibrillation (ICD-9: 427.31) at study entry were excluded (Fig. 1), and each patient was followed from the study entry date until the occurrence of $\mathrm{AF}$, cancer, death, or the end of the study period (December $31,2006)$, whichever came first. 
Fig. 1 Flow chart of the bisphosphonate cohort and casecontrol selection process

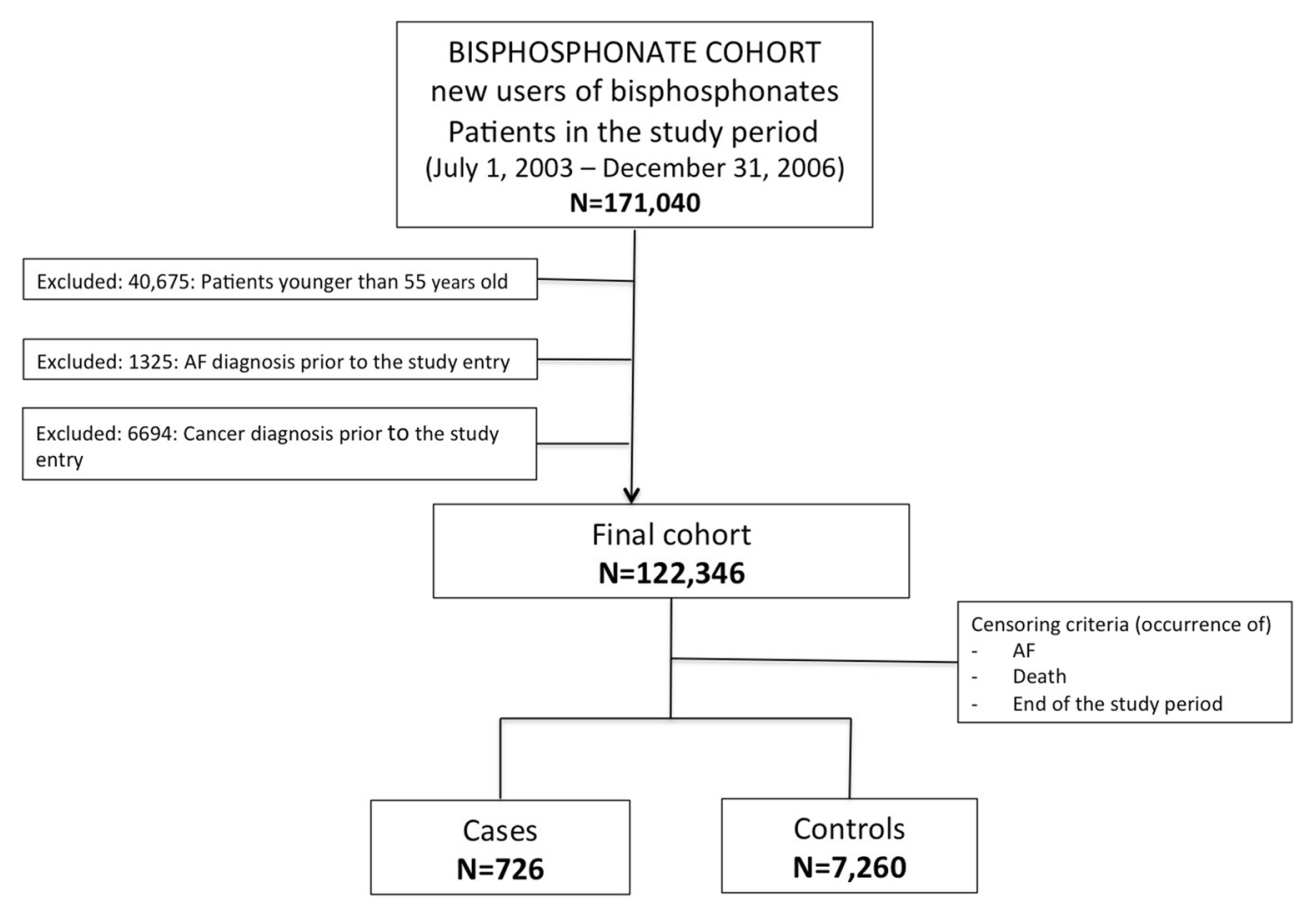

Study design

A case-control study nested in a cohort of new users of BP was performed in order to assess the risk of AF with BP use. All analyses were specified a priori in the study protocol.

\section{Case and control definitions}

A case was defined as a person with a primary discharge diagnosis of incidental AF (ICD-9: 427.31) during the study period. The date of a diagnosis of AF was considered as the index date (ID), and every case was matched with up to ten controls from the same cohort by age, sex, and time of cohort entry. Controls were selected using incidence density sampling. In general, this method consists of matching each case to a sample of those who are at risk at the time of case occurrence [28]. The index date of the controls was the same as those for the matched cases.

\section{Exposure assessment}

The area of interest included all BP marketed in Italy (ATC: M05BA* and M05BB*). The duration of exposure for each prescription was calculated by dividing the total amount of the drug dispensed by the defined daily drug specific dose (DDD). Three mutually exclusive categories were defined according to the temporal proximity of BP use: current use, if the estimated exposure to BP covered the index date or ended within 90 days prior to ID (i.e., carry-over period) [18]; recent use, if the exposure to BP ended between 91 and 180 days prior to ID; and past use, if the exposure to BP ended 181 and
365 days prior to ID. In addition, distant past use was used as reference category for all the analyses, if the exposure to BP had ended more than 365 days prior to ID.

\section{Covariates}

Known risk factors for AF were identified by searching among primary/secondary hospital discharge diagnoses or drug prescriptions. The presence of the following potential risk factors was evaluated for any period prior to ID: myocardial infarction, angina pectoris (defined by diagnosis or use of nitrates), heart failure, diabetes mellitus (defined by diagnosis or use of hypoglycemic drugs), hyperthyroidism, and prior use of antihypertensive drugs (including beta-blockers), lipid lowering drugs, antithyroid drugs, oral corticosteroids, and estrogens/hormone replacement therapy (HRT). In addition, a history of specific types of fractures was also considered: pelvic, hip, femur, tibia, fibula, and vertebral fractures.

Data analysis

Chi-square tests for categorical variables and Student $t$ tests for continuous variables were used to assess the differences between cases and controls. The incidence rate of diagnosis of $\mathrm{AF}$ in the cohort of new users of BP was calculated as the number of events occurring during follow-up divided by the cumulative person-years of exposure in the study period. A conditional logistic regression was performed to obtain the odds ratio (OR) as an estimate of the relative risk of $\mathrm{AF}$ for different BP exposure categories. ORs and $95 \% \mathrm{CI}$ were calculated for current, recent, and past use of bisphosphonates, 
whether separately, overall, and or single compound, using distant past use as the reference category. All of the potential risk factors which were univariately associated with the outcome $(p<0.05)$ were considered to be potential confounders and were included in the final multivariate models.

In addition, the potential effect modification of all covariates, including age and sex, were investigated. To rule out possible outcome misclassification in a sensitivity analysis, we excluded those patients who were treated with digoxin or warfarin as proxy for AF prior to the study entry date. To assess misclassifications of exposure, the effects of varying carry-over periods of 30 to 90 days were evaluated. The statistical analyses were performed using SPSS 18.0 (SPSS, Inc., Chicago, IL). For all of the analyses, statistical significance was set at $p<0.05$.

\section{Results}

Between July 1, 2003 and December 31, 2006, 171,040 new users of BP were identified. Of these, 122,346 (71.5\%) were retained in the final study cohort after considering the exclusion criteria (Fig. 1). In the final cohort of BP users, 726 $(0.6 \%)$ cases of AF were identified in the follow-up study. The incidence rate (IR) of AF diagnosis in the cohort of new users of BP was 3.65 per 1,000 person-years (PYs) $(95 \%$ CI, 3.40-3.92) (Table 1). The incidence rate was higher in males (4.59 per 1,000 PYs) than in females (3.51 per 1,000 PYs) and increased with advancing age. After matching by age, sex, and index date, 7,260 controls were identified.

The characteristics of the cases and controls are shown in Table 2. Most participants were females $(83.9 \%$ ) with a mean age at cohort entry of $76.9 \pm 7.6$ years. More than $60 \%$ of patients were over 75 years old. Cases were more likely to be affected by cardiovascular diseases and to be treated with lipid lowering drugs, oral corticosteroids, or antithyroid drugs than with controls.

After adjustment for potential confounders, an increased risk of AF among current users of BP was observed in comparison with those who had discontinued BP treatment for more than 1 year prior to ID (OR, 1.78; $95 \%$ CI, $1.46-$ 2.16). Using the same method of comparison, the risk of $A F$ also remained statistically significant in recent users of $\mathrm{BP}$ (OR, 1.70; $95 \% \mathrm{CI}, 1.27-2.28)$ and past users of BP (OR, $1.41 ; 95 \%$ CI, 1.07-185) (Table 3).

When stratifying by single compound use (Table 4), current users of alendronate (OR, 1.97; $95 \% \mathrm{CI}, 1.59-2.43)$ in combination with colecalciferol, and risedronate were associated with the highest risk of $\mathrm{AF}$ as compared with those who had stopped BP more than 1 year prior to the study entry date.

No significant effect modifications for age and sex were found. Furthermore, our main findings remained unchanged in a sensitivity analysis that excluded patients with a prescription of digoxin or warfarin before their cohort entry.

\section{Discussion}

To our knowledge, this is the first Italian multicenter study exploring the risk of $\mathrm{AF}$ in association with $\mathrm{BP}$ exposure. We found that current users of bisphosphonates are at a higher risk of AF compared to those who had stopped BP treatment at least 1 year before. However, a somewhat increased risk was observed for those who had stopped BP therapy within the prior year, suggesting that the biological effect of bisphosphonates on the heart, underlying a possible increase in AF risk, may persist for some time after the discontinuation of BP treatment. This finding is coherent with pharmacokinetic studies showing that BP remains in the bone

Table 1 Incidence rates of atrial fibrillation per 1,000 person-years by sex and age in the Italian cohort of new users of bisphosphonates ( $n=122,346)$

\begin{tabular}{|c|c|c|c|c|c|c|}
\hline Age groups (years) & $\begin{array}{l}\text { All } \\
\text { Cases/py }\end{array}$ & Incidence rate $(95 \% \mathrm{CI})$ & $\begin{array}{l}\text { Men } \\
\text { Cases/py }\end{array}$ & Incidence rate $(95 \% \mathrm{CI})$ & $\begin{array}{l}\text { Women } \\
\text { Cases/py }\end{array}$ & Incidence rate $(95 \% \mathrm{CI})$ \\
\hline $55-59$ years & $11 / 11,118$ & $0.99(0.53-1.71)$ & $2 / 1455$ & $1.37(0.27-4.41)$ & $9 / 9663$ & $0.93(0.46-1.7)$ \\
\hline $60-64$ years & $37 / 20,855$ & $1.77(1.27-2.42)$ & $7 / 2606$ & $2.69(1.20-5.27)$ & $30 / 18,249$ & $1.64(1.13-2.31)$ \\
\hline $65-69$ years & $72 / 31,766$ & $2.27(1.79-2.84)$ & $17 / 3850$ & $4.42(2.67-6.91)$ & $55 / 27,916$ & $1.97(1.5-2.54)$ \\
\hline 70-74 years & $122 / 37,805$ & $3.23(2.7-3.84)$ & $16 / 4597$ & $3.48(2.07-5.52)$ & $106 / 33,208$ & $3.19(2.63-3.84)$ \\
\hline $75-79$ years & $215 / 41,326$ & $5.20(4.55-5.93)$ & $42 / 5275$ & $7.96(5.82-10.65)$ & $173 / 36,051$ & $4.80(4.12-5.55)$ \\
\hline $80-84$ years & $157 / 34,882$ & $4.50(3.84-5.25)$ & $17 / 4731$ & $3.59(2.17-5.62)$ & $140 / 30,151$ & $4.64(3.92-5.46)$ \\
\hline 85 years & $112 / 21,119$ & $5.30(4.39-6.36)$ & $16 / 2969$ & $5.39(3.21-8.54)$ & $96 / 18,150$ & $5.29(4.31-6.43)$ \\
\hline Total & $726 / 198,871$ & $3.65(3.40-3.92)$ & $117 / 25,483$ & $4.59(3.81-5.48)$ & $609 / 173,388$ & $3.51(3.24-3.80)$ \\
\hline Standardized $^{\mathrm{a}}$ & & $2.44(1.91-3.12)$ & & & & \\
\hline
\end{tabular}

py person-years, $C I$ confidence interval

${ }^{\text {a }}$ Age — standardized incidence rate using World Health Organization reference population 
Table 2 Characteristics of cases of atrial fibrillation and controls
${ }^{*} p<0.05$ (significant)

a The data is mean \pm standard deviation

\begin{tabular}{|c|c|c|c|c|c|}
\hline Characteristics & $\begin{array}{l}\text { Cases } \\
n=726\end{array}$ & Percent & $\begin{array}{l}\text { Controls } \\
n=7260\end{array}$ & Percent & $p$ value \\
\hline Gender, female & 609 & 83.88 & 6090 & 83.88 & - \\
\hline $\mathrm{Age}^{\mathrm{a}}$ & $76.9 \pm 7.64$ & & $76.9 \pm 7.65$ & & - \\
\hline \multicolumn{6}{|l|}{ Age categories } \\
\hline $55-65$ years & 59 & 8.10 & 602 & 8.30 & \\
\hline $66-75$ years & 219 & 30.20 & 2155 & 29.70 & \\
\hline $76-85$ years & 361 & 49.70 & 3637 & 50.10 & \\
\hline$>85$ years & 87 & 12.00 & 866 & 11.90 & \\
\hline \multicolumn{6}{|l|}{ Cardiovascular diseases } \\
\hline Angina pectoris & 203 & 27.96 & 1215 & 19.95 & $<0.001^{*}$ \\
\hline Myocardial infarction & 20 & 2.75 & 92 & 1.51 & $0.001 *$ \\
\hline Heart failure & 80 & 11.02 & 199 & 3.27 & $<0.001^{*}$ \\
\hline Antihypertensive drugs & 627 & 86.36 & 5186 & 85.16 & $<0.001^{*}$ \\
\hline Diabetes mellitus & 84 & 11.57 & 780 & 12.81 & 0.494 \\
\hline Estrogen/hormone replace therapy & 35 & 4.82 & 334 & 5.48 & 0.787 \\
\hline Any type of fractures & 78 & 10.74 & 669 & 10.99 & 0.177 \\
\hline \multicolumn{6}{|l|}{ Prior use of drugs } \\
\hline Use of lipid lowering & 181 & 24.93 & 1497 & 20.62 & $0.007 *$ \\
\hline Oral corticosteroids & 271 & 37.33 & 2184 & 30.08 & $<0.001^{*}$ \\
\hline Antithyroid & 18 & 2.48 & 87 & 1.20 & $0.004 *$ \\
\hline
\end{tabular}

for years, potentially continuing to exert its effects on the bone as well as on the heart [29-32].

A double-blind RTC concurrent multicenter study of postmenopausal women with osteoporosis evaluated the effects of alendronate over a 10-year period. The results showed that patients who stopped alendronate at year 5 retained significant BMD values above baseline values in the last year of the study at lumbar spine, trochanter, total hip, and total body locations [33]. This implies that BP can have effects on bone composition even after the end of treatment. A study of children exposed to oral pamidronate for a mean period of 6.7 years demonstrated that after treatment

Table 3 Association between exposure to oral bisphosphonates and atrial fibrillation

\begin{tabular}{lllll}
\hline & $\begin{array}{l}\text { Cases } \\
n=726(\%)\end{array}$ & $\begin{array}{l}\text { Controls } \\
n=7260(\%)\end{array}$ & $\begin{array}{l}\text { Crude OR } \\
(95 \% \mathrm{CI})\end{array}$ & $\begin{array}{l}\text { Adjusted OR } \\
(95 \% \mathrm{CI})\end{array}$ \\
\hline Current & $373(51)$ & $3129(43)$ & $1.71(1.41-2.08)$ & $1.78(1.46-2.16)$ \\
Recent & $78(11)$ & $667(09)$ & $1.68(1.26-2.23)$ & $1.70(1.27-2.28)$ \\
Past & $96(13)$ & $1006(14)$ & $1.38(1.06-1.80)$ & $1.41(1.07-1.85)$ \\
$\begin{array}{c}\text { Distant } \\
\text { past }\end{array}$ & $179(25)$ & $2458(34)$ & Reference & Reference \\
\hline
\end{tabular}

Adjusted for angina pectoris, heart failure, antihypertensive drugs, myocardial infarction, use of lipid lowering drugs, oral corticosteroids, and antithyroid drugs. Categories of users: current (0-90 days prior to index date), recent (91-180 days), past (181-365 days), and distant past (365+days)

$C I$ confidence interval, $O R$ odds ratio withdrawal, BP was detectable in their urine after an average of almost 8 years [34].

Various bisphosphonates differ in terms of the mineralbinding and cellular effects which may result in different clinical effects [35, 36]. In our study, current users of alendronate and risedronate had the highest increases in AF risk when compared to those patients who had stopped bisphosphonates for more than 1 year.

It is well known that observational studies cannot randomly assign exposure, and this limitation can lead to confounding effects because of different baseline risks for the exposure categories. In general, patients who are treated with bisphosphonates may have a higher baseline risk of AF compared to those who are not treated. In our study, by choosing as reference group those BP users who had stopped treatment more than 1 year before, we attempted to minimize the effects of confounding by indication. However, this possibility of risk cannot be totally ruled out. Baseline risk can also differ between patients who stopped treatment versus those who continued with BP treatment. In comparison with other studies using non-use of BP as the point of reference, our study is likely to be much less affected by this type of confounding. Although we could not address all possible confounders, we adjusted the multivariate analyses for the most important confounding factors.

There exists a large body of evidence about the association between AF and BP (Appendix 1). In particular, our results are in line with the study by Abrahamsen et al. [11], which found 
Table 4 Associations between atrial fibrillation and oral bisphosphonates by single compound

\begin{tabular}{|c|c|c|c|c|}
\hline & $\begin{array}{l}\text { Cases } \\
n=726(\%)\end{array}$ & $\begin{array}{l}\text { Controls } \\
n=7260(\%)\end{array}$ & $\begin{array}{l}\text { Crude OR } \\
(95 \% \text { CI })\end{array}$ & $\begin{array}{l}\text { Adjusted OR* } \\
(95 \% \mathrm{CI})\end{array}$ \\
\hline \multicolumn{5}{|l|}{ Current users (0-90 days) } \\
\hline Etidronate & $0(0.00)$ & $7(0.10)$ & (NA) & NA \\
\hline Clodronate & $4(0.55)$ & $34(0.47)$ & $1.66(0.58-4.76)$ & $1.68(0.58-4.88)$ \\
\hline Alendronate & $255(35.12)$ & $1930(26.58)$ & $1.88(1.53-2.31)$ & $1.97(1.59-2.43)$ \\
\hline Risedronate & $82(11.29)$ & $868(11.96)$ & $1.36(1.03-1.79)$ & $1.35(1.01-1.79)$ \\
\hline Neridronic acid & $12(1.65)$ & $119(1.64)$ & $1.43(0.77-2.66)$ & $1.46(0.78-2.75)$ \\
\hline Alendronate plus colecalciferol & $15(2.07)$ & $132(1.82)$ & $1.67(0.94-2.96)$ & $1.79(1.00-3.21)$ \\
\hline More than one BP within the same period of time. & $5(0.69)$ & $39(0.54)$ & $1.83(0.71-4.7)$ & $2.07(0.79-5.46)$ \\
\hline \multicolumn{5}{|l|}{ Recent users (91-180 days) } \\
\hline Etidronate & $0(0.00)$ & $6(0.08)$ & (NA) & NA \\
\hline Clodronate & $3(0.41)$ & $12(0.17)$ & $3.42(0.95-12.23)$ & $4.12(1.1-15.36)$ \\
\hline Alendronate & $44(6.06)$ & $420(5.79)$ & $1.50(1.06-2.13)$ & $1.49(1.04-2.14)$ \\
\hline Risedronate & $20(2.75)$ & $165(2.27)$ & $1.76(1.07-2.88)$ & $1.87(1.13-3.08)$ \\
\hline Neridronic acid & $1(0.14)$ & $43(0.59)$ & (NA) & NA \\
\hline Alendronate plus colecalciferol & $7(0.96)$ & $16(0.22)$ & $6.72(2.63-17.17)$ & $6.63(2.48-17.70)$ \\
\hline More than one BP within the same period of time. & $3(0.41)$ & $3(0.04)$ & $13.64(2.73-68.12)$ & $11.38(2.24-57.73)$ \\
\hline \multicolumn{5}{|l|}{ Past users (181-365 days) } \\
\hline Etidronate & $0(0.00)$ & $6(0.08)$ & (NA) & NA \\
\hline Clodronate & $1(0.14)$ & $16(0.22)$ & (NA) & NA \\
\hline Alendronate & $63(8.68)$ & $635(8.75)$ & $1.44(1.06-1.95)$ & $1.46(1.06-1.99)$ \\
\hline Risedronate & $28(3.86)$ & $251(3.46)$ & $1.62(1.06-2.48)$ & $1.63(1.05-2.51)$ \\
\hline Neridronic acid & $2(0.28)$ & $76(1.05)$ & (NA) & NA \\
\hline Alendronate plus colecalciferol & $0(0.00)$ & $13(0.18)$ & (NA) & NA \\
\hline More than one BP within the same period of time. & $2(0.28)$ & $11(0.15)$ & (NA) & NA \\
\hline Distant past user of any $\mathrm{BP}>365$ days & $179(24.66)$ & $2458(33.90)$ & Reference & Reference \\
\hline
\end{tabular}

Adjusted for angina pectoris, myocardial infarction, heart failure, antihypertensive drugs, use of lipid lowering drugs, oral corticosteroids, and antithyroid therapy

an association between oral $\mathrm{BP}$ and $\mathrm{AF}$ in patients with fractures (hazard ratio, 1.18; $95 \%$ CI, 1.08-1.29). Similar results were reported in a case-control study ("The Group Health study"), which documented higher AF risk for alendronate users compared with non-users of BP (OR, 1.86; $95 \% \mathrm{CI}$, 1.09-3.15). The patient characteristics were similar to those in our study in terms of age and the burden of cardiovascular diseases [13]. In line with our findings, a recent metaanalysis of six observational studies (OR, 1.27; $95 \% \mathrm{CI}$, 1.16-1.39) and six RCT (OR, 1.40; $95 \%$ CI, 1.02-1.93) has reported an increased risk of AF among users of BP [37].

On the contrary, a Danish study, using healthcare databases, showed an association between the use of etidronate and alendronate and AF that was not statistically significant when compared to non-users of BP. [18]. It is possible that differences in study design and different prescription patterns for BP may account for the differences observed between the Danish study and ours.

The biological mechanisms explaining possible increases in the risk of $\mathrm{AF}$ in $\mathrm{BP}$-treated patients is still unknown. It has been suggested that parenteral administration of BP can trigger inflammation via cytokines, which might lead to a broad spectrum of cardiovascular effects including AF [14]. Another study has suggested that alendronate-related changes of cytokine production are mediated through the regulation of transcriptional activity [38]. In addition, evidence from autopsies has showed that long-term use of oral BP, such as alendronate can lead to calcification in the conducting system and atria [37]. A recent study [39] conducted on oral mucosa from BP-treated patients reported a significantly elevated production of cytokines (including IL-6). Interestingly, an in vitro study showed that atrial and, to a lesser extent, ventricular cardiomyocytes developed abnormalities in calcium dynamics when exposed to alendronate [40].

In our study, some limitations have to be acknowledged: the data sources of the study did not capture the use of zoledronic acid, which is only intravenously administered in hospitals in Italy. We used dispensing data to evaluate the exposure status of the patients, and we had no information about their actual use of the medications. If the 
exposure misclassification exists due to poor compliance, it is however likely to be randomly distributed among the cases and controls, eventually leading to an underestimation of the true effects of BP. For some BP users, the exposure data were too limited and did not allow for robust risk estimates. Nevertheless, a wide range of BP use has been investigated, and since the database network which was used in the study comprises only information on hospital discharge diagnoses, it is likely that we captured only the more severe cases of AF that led to hospitalization, which in turn reduces the generalizability of our findings.

We also excluded cancer patients because they are at a higher risk of atrial fibrillation [41], and these patients are difficult to trace by using administrative databases because of their possibly long stays in hospitals and other institutions, especially at advanced stages of the disease. Finally, cancer patients who receive bisphosphonates for the treatment of bone metastasis are generally treated in hospital with intravenous administrations of zoledronic acid and, as such, the use of this drug cannot be captured using our data sources, which were available only for outpatient prescriptions. For this reason, exposure to bisphosphonates in cancer patients would likely be misclassified, and we therefore preferred not to include these patients in the study, even if this decision limited the generalizability of our results.

We did not validate the AF cases because according to Jensen et al. [42], the ICD-9 code 427.31 performs well in identifying AF in electronic health databases. Jensen's study evaluated 16 studies, of which 14 were comparable and yielded a positive predictive value (PPV) that was between 70 and $96 \%$. In addition, the exclusion of patients who were treated with digoxin and warfarin (as proxies of AF) did not change the main risk estimates, ruling out major effects of outcome misclassifications in the observed findings.

Current guidelines for the use of bisphosphonates do not specify to have early control for possible AF. However, we acknowledge that a standard clinical evaluation of the patients at the beginning of BP treatment may occasionally lead to diagnosis of hitherto hidden AF. The potential surveillance bias was however minimized in our study by conducting a case-control study nested in a cohort of new users of BP.

In conclusion, our results suggest that the use of bisphosphonates is associated with an almost double increase in the risk of AF when our population is compared to those who had stopped BP treatment before at least 1 year. This risk is especially elevated for current users of alendronate and risedronate. Moreover, the risk seems not to disappear immediately after stopping BP therapy, which may suggest either long-term effects of BP due to bone accumulation and slow release in the blood, or confounding by indication.

Acknowledgments The authors are very grateful to Dr. Lilith Haynes for the time devoted to review and edit our manuscript.
Conflicts of interest The study was supported by Agenzia Italiana del Farmaco (AIFA - grant FARM06R9YY), Rome, Italy. Dr. Schuemie joined Janssen Research \& Development since completing the research described here. Lizbeth Herrera, Ingrid Leal, Francesco Lapi, Giampiero Mazzaglia, Vincenzo Arcoraci, Francesco Cipriani, Emiliano Sessa, Alberto Vaccheri, Carlo Piccinni, Tommaso Staniscia, Annarita Vestri, Mauro Di Bari, Giovanni Corrao, Antonella Zambon, Dario Gregori, Flavia Carle, Miriam Sturkenboom, and Gianluca Trifiro declare that they have no conflict of interest.

Open Access This article is distributed under the terms of the Creative Commons Attribution Noncommercial License which permits any noncommercial use, distribution, and reproduction in any medium, provided the original author(s) and the source are credited.

\section{References}

1. Recker RR, Lewiecki EM, Miller PD, Reiffel J (2009) Safety of bisphosphonates in the treatment of osteoporosis. Am J Med $122(2$ Suppl):S22-S32

2. Boonen S (2009) Impact of treatment efficacy and dosing frequency on cost-effectiveness of bisphosphonate treatment for osteoporosis: a perspective. Curr Med Res Opin 25(10):2335-2341

3. Delmas PD, Munoz F, Black DM, Cosman F, Boonen S, Watts NB, Kendler D, Eriksen EF, Mesenbrink PG, Eastell R (2009) Effects of yearly zoledronic acid $5 \mathrm{mg}$ on bone turnover markers and relation of PINP with fracture reduction in postmenopausal women with osteoporosis. J Bone Miner Res 24(9):1544-1551

4. McClung M, Harris ST, Miller PD, Bauer DC, Davison KS, Dian L, Hanley DA, Kendler DL, Yuen CK, Lewiecki EM (2013) Bisphosphonate therapy for osteoporosis: benefits, risks, and drug holiday. Am J Med 126(1):13-20

5. Jansen JP, Bergman GJ, Huels J, Olson M (2011) The efficacy of bisphosphonates in the prevention of vertebral, hip, and nonvertebralnonhip fractures in osteoporosis: a network meta-analysis. Semin Arthritis Rheum 40 (4):275-284 e271-272

6. Pazianas M, Cooper C, Ebetino FH, Russell RG (2010) Long-term treatment with bisphosphonates and their safety in postmenopausal osteoporosis. Ther Clin Risk Manag 6:325-343

7. van Boven JF, de Boer PT, Postma MJ, Vegter S (2013) Persistence with osteoporosis medication among newly-treated osteoporotic patients. J Bone Miner Metab

8. Solomon DH, Rekedal L, Cadarette SM (2009) Osteoporosis treatments and adverse events. Curr Opin Rheumatol 21(4):363-368

9. Rizzoli R, Reginster JY, Boonen S, Breart G, Diez-Perez A, Felsenberg D, Kaufman JM, Kanis JA, Cooper C (2011) Adverse reactions and drug-drug interactions in the management of women with postmenopausal osteoporosis. Calcif Tissue Int 89(2):91-104

10. Abrahamsen B (2010) Bisphosphonate adverse effects, lessons from large databases. Curr Opin Rheumatol 22(4):404-409

11. Abrahamsen B, Eiken P, Brixen K (2009) Atrial fibrillation in fracture patients treated with oral bisphosphonates. J Intern Med 265(5): 581-592

12. Black DM, Delmas PD, Eastell R, Reid IR, Boonen S, Cauley JA, Cosman F, Lakatos P, Leung PC, Man Z, Mautalen C, Mesenbrink P, $\mathrm{Hu} \mathrm{H}$, Caminis J, Tong K, Rosario-Jansen T, Krasnow J, Hue TF, Sellmeyer D, Eriksen EF, Cummings SR (2007) Once-yearly zoledronic acid for treatment of postmenopausal osteoporosis. N Engl J Med 356(18):1809-1822 
13. Heckbert SR, Li G, Cummings SR, Smith NL, Psaty BM (2008) Use of alendronate and risk of incident atrial fibrillation in women. Arch Intern Med 168(8):826-831

14. Cummings SR, Schwartz AV, Black DM (2007) Alendronate and atrial fibrillation. N Engl J Med 356(18):1895-1896

15. John Camm A (2010) Review of the cardiovascular safety of zoledronic acid and other bisphosphonates for the treatment of osteoporosis. Clin Ther 32(3):426-436

16. Cummings SR, Black DM, Thompson DE, Applegate WB, BarrettConnor E, Musliner TA, Palermo L, Prineas R, Rubin SM, Scott JC, Vogt T, Wallace R, Yates AJ, LaCroix AZ (1998) Effect of alendronate on risk of fracture in women with low bone density but without vertebral fractures: results from the Fracture Intervention Trial. JAMA 280(24):2077-2082

17. Huang WF, Tsai YW, Wen YW, Hsiao FY, Kuo KN, Tsai CR (2010) Osteoporosis treatment and atrial fibrillation: alendronate versus raloxifene. Menopause 17(1):57-63

18. Sorensen HT, Christensen S, Mehnert F, Pedersen L, Chapurlat RD, Cummings SR, Baron JA (2008) Use of bisphosphonates among women and risk of atrial fibrillation and flutter: population based case-control study. BMJ 336(7648):813-816

19. Rhee CW, Lee J, Oh S, Choi NK, Park BJ (2012) Use of bisphosphonate and risk of atrial fibrillation in older women with osteoporosis. Osteoporos Int 23(1):247-254

20. Vestergaard P, Schwartz K, Pinholt EM, Rejnmark L, Mosekilde L (2010) Risk of atrial fibrillation associated with use of bisphosphonates and other drugs against osteoporosis: a cohort study. Calcif Tissue Int 86(5):335-342

21. Bunch TJ, Anderson JL, May HT, Muhlestein JB, Horne BD, Crandall BG, Weiss JP, Lappe DL, Osborn JS, Day JD (2009) Relation of bisphosphonate therapies and risk of developing atrial fibrillation. Am J Cardiol 103(6):824-828

22. Administration UFaD (2007) Update of Safety Review Follow-up to the October 1, 2007 Early Communication about the Ongoing Safety Review of Bisphosphonates. http:/www.fda.gov/Drugs/DrugSafety/ PostmarketDrugSafetyInformationforPatientsandProviders/ DrugSafetyInformationforHeathcareProfessionals/ucm136201.htm. Accessed 07-23-2013 2013

23. Ringborg A, Nieuwlaat R, Lindgren P, Jonsson B, Fidan D, Maggioni AP, Lopez-Sendon J, Stepinska J, Cokkinos DV, Crijns HJ (2008) Costs of atrial fibrillation in five European countries: results from the Euro Heart Survey on atrial fibrillation. Europace 10(4):403-411

24. Heeringa $J$ (2010) Atrial fibrillation: is the prevalence rising? Europace 12(4):451-452

25. Camm AJ, Camm CF, Savelieva I (2012) Medical treatment of atrial fibrillation. J Cardiovasc Med (Hagerstown) 13(2):97-107

26. Camm AJ (2012) Atrial fibrillation and risk. Clin Cardiol 35(Suppl 1):1-2

27. Lapi F, Cipriani F, Caputi AP, Corrao G, Vaccheri A, Sturkenboom MC, Di Bari M, Gregori D, Carle F, Staniscia T, Vestri A, Brandi M, Fusco V, Campisi G, Mazzaglia G (2013) Assessing the risk of osteonecrosis of the jaw due to bisphosphonate therapy in the secondary prevention of osteoporotic fractures. Osteoporos Int $\mathrm{J}$
Established Result Cooperation Between Eur Found Osteoporos Natl Osteoporos Found U S A 24(2):697-705

28. Beaumont JJ, Steenland K, Minton A, Meyer S (1989) A computer program for incidence density sampling of controls in case-control studies nested within occupational cohort studies. Am J Epidemiol 129(1):212-219

29. Watts NB, Diab DL (2010) Long-term use of bisphosphonates in osteoporosis. J Clin Endocrinol Metab 95(4):1555-1565

30. Salari P, Abdollahi M (2012) Long term bisphosphonate use in osteoporotic patients; a step forward, two steps back. J Pharm Pharm Sci 15(2):305-317

31. McClung M, Harris ST, Miller PD, Bauer DC, Davison KS, Dian L, Hanley DA, Kendler DL, Yuen CK, Lewiecki EM (2013) Bisphosphonate therapy for osteoporosis: benefits, risks, and drug holiday. Am J Med 126(1):13-20

32. Whitaker M, Guo J, Kehoe T, Benson G (2012) Bisphosphonates for osteoporosis - where do we go from here? N Engl J Med 366(22): 2048-2051

33. Bone HG, Hosking D, Devogelaer JP, Tucci JR, Emkey RD, Tonino RP, Rodriguez-Portales JA, Downs RW, Gupta J, Santora AC, Liberman UA (2004) Ten years' experience with alendronate for osteoporosis in postmenopausal women. N Engl J Med 350(12): 1189-1199

34. Papapoulos SE, Cremers SC (2007) Prolonged bisphosphonate release after treatment in children. N Engl J Med 356(10):1075-1076

35. Russell RG (2007) Bisphosphonates: mode of action and pharmacology. Pediatrics 119(Suppl 2):S150-S162

36. Russell RG (2011) Bisphosphonates: the first 40 years. Bone 49(1): $2-19$

37. Sharma A, Chatterjee S, Arbab-Zadeh A, Goyal S, Lichstein E, Ghosh J, Aikat S (2013) Risk of serious atrial fibrillation and stroke with use of bisphosphonates: evidence from a meta-analysis. Chest

38. Tamai R, Sugiyama A, Kiyoura Y (2011) Alendronate regulates cytokine production induced by lipid A through nuclear factor-kappaB and Smad 3 activation in human gingival fibroblasts. J Periodontal Res 46(1):13-20

39. Mozzati M, Martinasso G, Maggiora M, Scoletta M, Zambelli M, Carossa S, Oraldi M, Muzio G, Canuto RA (2013) Oral mucosa produces cytokines and factors influencing osteoclast activity and endothelial cell proliferation, in patients with osteonecrosis of jaw after treatment with zoledronic acid. Clin Oral Investig 17(4):1259-1266

40. Kemeny-Suss N, Kasneci A, Rivas D, Afilalo J, Komarova SV, Chalifour LE, Duque G (2009) Alendronate affects calcium dynamics in cardiomyocytes in vitro. Vasc Pharmacol 51(5-6):350-358

41. Farmakis D, Parissis J, Filippatos G (2014) Insights into onco-cardiology: atrial fibrillation in cancer. J Am Coll Cardiol 63(10):945-953

42. Jensen PN, Johnson K, Floyd J, Heckbert SR, Carnahan R, Dublin S (2012) A systematic review of validated methods for identifying atrial fibrillation using administrative data. Pharmacoepidemiol Drug Saf 21(Suppl 1):141-147 